\title{
Children's cartography: what is a map according to children?
}

\author{
Heather Swienton $^{\mathrm{a}, *}$, Alberto Giordano ${ }^{\mathrm{b}}$, Ron Hagelman ${ }^{\mathrm{c}}$, Shadi Maleki ${ }^{\mathrm{d}}$ \\ ${ }^{a}$ Department of Geography, Texas State University, has41@txstate.edu \\ ${ }^{b}$ Department of Geography, Texas State University, a.giordano@txstate.edu \\ ${ }^{c}$ Department of Geography, Texas State University, rhagelman@txstate.edu \\ ${ }^{d}$ Department of Geography, Texas State University, s_m413@txstate.edu \\ * Corresponding author
}

Keywords: Cartography and children, Map design, Mental maps

\begin{abstract}
:
Cartography provides a powerful and creative means to visualize and comprehend the world around us. Beyond the feat of navigation, maps have been tools of war, instruments of education, and mediums for art. Maps matter. But what is a map? In this presentation, we offer one answer to this question from the perspective of approximately 765 schoolchildren aged 6 to 14 who visited the grounds of the Meadows Center for Water and the Environment, located on the campus of Texas State University in San Marcos, Texas. The children were on school trips conducted in the second half of 2017. At the end of their visit, these children were asked to draw a map of their field trip experience. They were provided colored markers, pens, and paper to map their day and describe their map in writing, but no other instructions were provided. The resulting maps were then collected, catalogued, and preserved in both paper and digital format. The children who participated in this experiment varied in age, race, gender, and socio-economic status. They came from different parts of Texas, including rural areas and big cities. Some were familiar with the area, but most were not.

Although these differences are important, in this presentation we set them aside to concentrate only on the artifacts the children produced, which we are analyzing from a map design perspective. More specifically, we seek to answer the question "for our child cartographers, what is a map?" by closely examining what children materially create when asked to make a map - the what and how of the mapmaking process:
\end{abstract}

What is being mapped? What landforms are mapped? What roads, trails, etc.? Are the children including flora and/or fauna? Are the children including the natural environment and/or the built environment? Are they mapping events or only physical features, i.e., are they mapping time?

How is it being mapped? Do the children demonstrate knowledge of cartographic rules and conventions? How do they use color, size, shape, and the other visual variables? At what scale do they create the map? What is the geometric perspective they use?

At the time of this writing, we are analyzing individual maps. Preliminary results indicate that children mapped anthropogenic elements more so than natural elements, and their overall use of cartographic conventions was limited. The maps vary greatly in terms of scale, detail, and the features of the landscape the children decided to map, as well as how they chose to represent (or not) the relationship between space and time. In our research plan, this study is intended to lay the initial groundwork not only to better understand what a map is to children, but also to open the door to future investigations related to children's geographic education, psychology and the development of spatial cognition, and cartographic literacy. We are also interested in exploring how the children's personal geography (school district, zip code) and age (grade level) impact their cartographic understanding and practice.

We wish to acknowledge that this research is part of a multi-year study originated through the efforts of several students and faculty (Shadi Maleki, Aspen Navarro, Emily Warren, and Dr. Ronald Hagelman III) at Texas State University in partnership with the Meadows Center. The original study was designed to explore children's perception, expressions of and relationship with nature through map-making. We owe a big debt of gratitude to our colleagues at Texas State and of course to the hundreds of children, teachers, and educators who participated in the experiment. 